\title{
Thermophysical aspects of reconstruction of cold roof spaces
}

\author{
Oleksandr Semko ${ }^{*}$, Oleg Yurin ${ }^{1}$, Yurii Avramenko ${ }^{1}$, and Serhii Skliarenko ${ }^{1}$ \\ ${ }^{1}$ Architecture and Urban Construction Department, Poltava National Technical Yuri Kondratyuk \\ University, Pershotravnevyi avenue, 24, 36011 Poltava, Ukraine
}

\begin{abstract}
The results of theoretical studies of thermal modernization of cold roof floor. The designs of overlap of long-life roofs of public buildings were considered. Overlap of these buildings are made by wooden or concrete beams and made of concrete slabs with upward edges. The problems of thermal modernization of these designs are consideration of the impact of heat-conducting inclusions on the resistance to heat. The heat-conducting inclusions of constructions are beams and vertical edges of the slabs. The results of calculations of the temperature fields were used for the analysis. The research was carried for the two temperature zones which Ukraine's territory is divided into. The analysis of thermal protection level of structures overlap was made. The magnitude of the impact of heat-conducting inclusions on resistance to heat after thermal modernization of cold roof floor was observed. The analysis showed that the thermal protection properties of structures less than standard, therefore the insulation of areas with heat-conducting inclusions is required. The options of insulation of these areas were considered. The optimal insulation options with the least amount of additional insulation over the heat conductive areas were selected.
\end{abstract}

One of the main tasks of external walling designing is to provide a normalized level of thermal and moisture conditions. However, when determining the thickness of the heatinsulation material of the walling the availability of the heat conductive inclusions with the thermal protection level smaller than in areas without it is ignored. In the roof floor buildings with long-life heat-conducting inclusions related to the vertical edges of concrete slabs, wooden beams and reinforced concrete. Ignoring of the properties of these areas leads to higher overall heat loss through external building walling. In addition to high heat in these areas there are such negative phenomena as lowering the temperature of the inner surface and increasing the amplitude of temperature variations on this surface. Increasing of the thermal-resisting properties is possible by additional insulation of heat conductive areas inclusions.

There are works of various authors dedicated to the issue of increasing the thermalresisting properties of heat conductive areas inclusions of the external walling [1,2]. Such as $[3,4]$ performed a series of tests of thermal external wall panels of residential and civil buildings. During the study the impact of "cold bridges" on the thermal quality of external

\footnotetext{
* Corresponding author: al.vl.semko@gmail.com
} 
wall panels, developed technical solutions to their elimination $[5,6]$. The approbation of theoretical methods for calculating the thermal characteristics of prefabricated buildings were performed. The results of thermal performance of prefabricated building walls were obtained [7]. Scientists [8] analyzed the thermal field forming of the exterior wall of frontal concrete panel with mounting hooks. Scientists $[9,10]$ researched the thermal qualities of sandwich panels with flexible links and reinforced concrete dowels.

The authors have concentrated on sections of wall constructions and walling complex configurations in the publications devoted to research the ways to improve the thermal barrier properties of the enclosure with heat conductive inclusions. The design of long-life roof floor buildings, requiring the thermal modernization and bringing them to the thermal regulations were not considered.

The work objective is to determine the optimal size of additional insulation sections with heat conductive inclusions for roof floor construction of long-life public buildings with their thermal modernization.

There are often could be the design with conductive areas of the cold roof spaces of buildings with significant lifetime. These structures include spaces on wooden or concrete beams and slabs of reinforced concrete with the upward edges (fig. 1).

a)

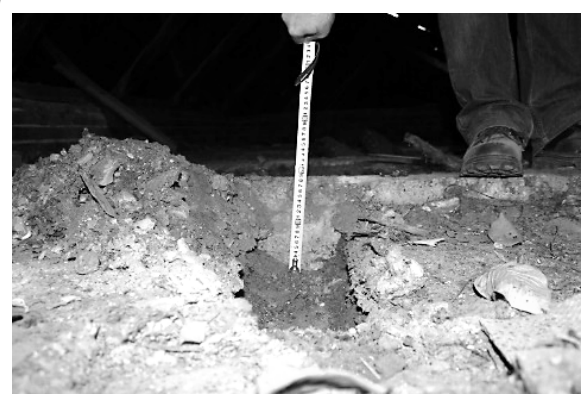

b)

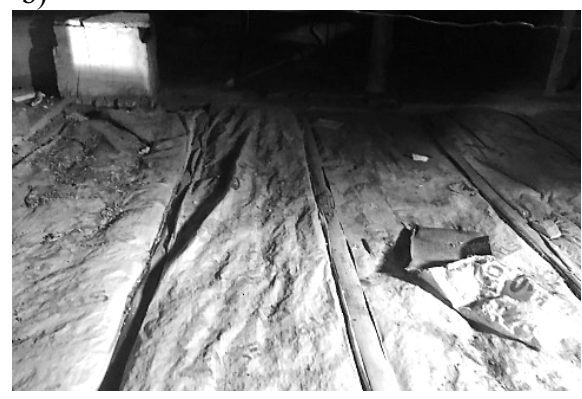

Fig. 1. The spaces of roof of buildings: a) construction of concrete slabs with upwards edges; b) - the wooden beams.

Drawing of these structures are shown in Figure 2.

The areas with heat conductive inclusions include the vertical edges of concrete slabs, wooden beams and reinforced concrete. When thermal modernization of such structures the availability of these sites and providing the additional insulation to ensure their compliance with the rules of thermal protection requirements listed in [6] shall be taken into account.

Analysis of the state of the existing structures was implemented by calculating the temperature fields. The thermal conductivity of the materials taken for conditions B. The research was carried out for two temperature zones. The estimated internal air temperature was taken as $T_{i n}=20{ }^{\circ} \mathrm{C}$, and relative humidity as $\varphi_{i n}=55 \%$. The temperature fields of cold roof spaces is in $2{ }^{\circ} \mathrm{C}$ less then the ambient temperature estimated. The temperature fields of cold roof spaces in first temperature field is shown in Figure 3.

The results of calculation are shown in Table 1.

According to [6] for external walling buildings the following requirements of thermal insulation shall be carried out: $R_{\text {Ered }} \geq R_{q \text { min }}, \Delta T_{\text {red }} \leq \Delta T_{\text {sh }}, T_{\text {in, min }}>T_{d}$.

As shown in Table 1, the first and the second thermal requirement does not apply in all the structures of cold roof overlap. So that all the structures require the thermal modernization. For the cold roof overlap structures thermal modernization there was the SUPERROCK insulation utility with the density of $\rho_{o}=38 \mathrm{~kg} / \mathrm{m}^{3}$ and thermal conductivity $\lambda=0,035 \mathrm{~W} /(\mathrm{m} \cdot \mathrm{K})$ and thermal. Typically, when the thermal modernization of constructions is applied the insulation existing (slag in the considered design) shall be removed. 
a)

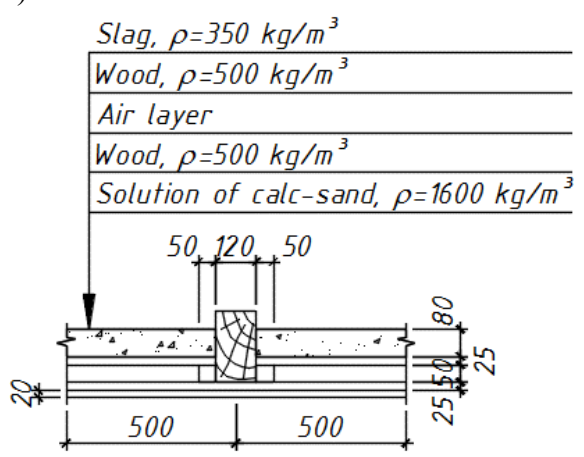

b)

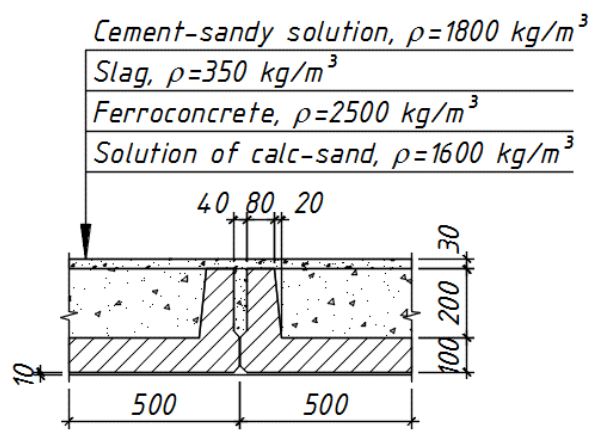

c)

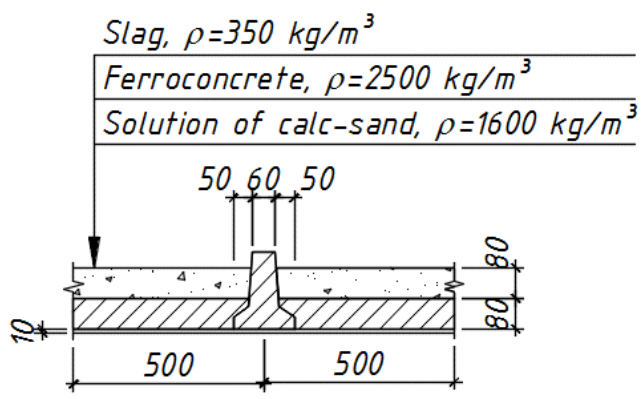

Fig. 2. The spaces of roof of buildings: a) - on the wooden beams; b) - on concrete slabs with upwards edges; c) - on reinforced concrete beams.

a)

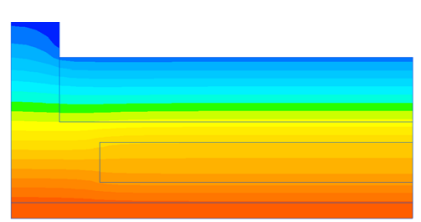

b)

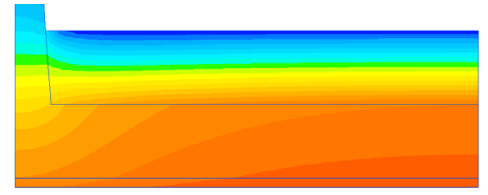

c)

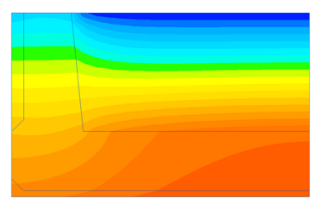

Fig. 3. The temperature fields of cold roof spaces in first temperature field: a) - on the wooden beams; b) - on concrete slabs with upwards edges; c) - on reinforced concrete beams.

According to the calculation of heating-performance without areas with heat conductive inclusions the thickness of insulation is (see Table 2).

Typically, the insulation utility is placed between the construction beams or ribs, and other sides could be open.

As shown in Table 3 with this version of insulation, the first requirement for heat protection is not fulfilled for all the constructions considered. In addition, when applying plates with upwards ribs, the second requirement is not fulfilled. That is, the insulation of areas with heat-conducting inclusions is mandatory. 
Table 1. Thermal characteristic of the cold roof spaces.

\begin{tabular}{|c|c|c|c|c|}
\hline \multirow[b]{2}{*}{ 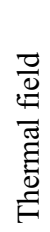 } & \multirow[b]{2}{*}{ Indicator } & \multicolumn{3}{|c|}{ The design of the cold roof spaces } \\
\hline & & For wooden beams & $\begin{array}{l}\text { For reinforced } \\
\text { concrete beams }\end{array}$ & $\begin{array}{c}\text { Made of concrete } \\
\text { slabs with upward } \\
\text { edges }\end{array}$ \\
\hline \multirow{6}{*}{1} & $R_{\text {Ered }}, \mathrm{m}^{2} \cdot \mathrm{K} / \mathrm{W}$ & 1,1 & 0,558 & 0,756 \\
\hline & $R_{q \min }, \mathrm{m}^{2} \cdot \mathrm{K} / \mathrm{W}$ & \multicolumn{3}{|c|}{4,95} \\
\hline & $\Delta T_{\text {red }},{ }^{\circ} \mathrm{C}$ & 4,2 & 8,2 & 6,1 \\
\hline & $\Delta T_{s h},{ }^{\circ} \mathrm{C}$ & \multicolumn{3}{|c|}{4} \\
\hline & $T_{\text {in }, \min ,}{ }^{\circ} \mathrm{C}$ & 15,7 & 12,8 & 15,6 \\
\hline & $T_{d},{ }^{\circ} \mathrm{C}$ & \multicolumn{3}{|c|}{10,7} \\
\hline \multirow{6}{*}{2} & $R_{\text {Ered }}, \mathrm{m}^{2} \cdot \mathrm{K} / \mathrm{W}$ & 1,1 & 0,558 & 0,756 \\
\hline & $R_{q \min }, \mathrm{m}^{2} \cdot \mathrm{K} / \mathrm{W}$ & \multicolumn{3}{|c|}{4,5} \\
\hline & $\Delta T_{\text {red }},{ }^{\circ} \mathrm{C}$ & 3,9 & 7,6 & 5,6 \\
\hline & $\Delta T_{s h},{ }^{\circ} \mathrm{C}$ & \multicolumn{3}{|c|}{4} \\
\hline & $T_{\text {in }, \min },{ }^{\circ} \mathrm{C}$ & 16 & 13,4 & 15,9 \\
\hline & $T_{d},{ }^{\circ} \mathrm{C}$ & \multicolumn{3}{|c|}{10,7} \\
\hline
\end{tabular}

Table 2. The thickness of insulation according to thermal calculations and excluding the areas with heat conductive inclusions as follows.

\begin{tabular}{|c|c|c|c|c|}
\hline \multirow{2}{*}{ Thermal field } & \multirow{2}{*}{ Indicator } & \multicolumn{3}{|c|}{ The design of the cold roof spaces } \\
\cline { 3 - 5 } & & By wooden beams & $\begin{array}{c}\text { By reinforced } \\
\text { concrete beams }\end{array}$ & $\begin{array}{c}\text { Made of concrete } \\
\text { slabs with upward } \\
\text { edges }\end{array}$ \\
\hline 1 & \multirow{2}{*}{$h_{\text {ins }}, \mathrm{m}$} & 0,16 & 0,17 & 0,17 \\
\hline 2 & $\begin{array}{c}R_{\Sigma}, \\
\mathrm{m}^{2} \cdot \mathrm{K} / \mathrm{W}\end{array}$ & 0,14 & 0,15 & 0,15 \\
\cline { 3 - 5 } & & 5,209 & 5,105 & 5,115 \\
\hline 2 & & 4,638 & 4,534 & 4,544 \\
\hline
\end{tabular}

As shown in Table 3 with this version of insulation, the first requirement for heat protection is not fulfilled for all the constructions considered. In addition, when applying plates with upwards ribs, the second requirement is not fulfilled. That is, the insulation of areas with heat-conducting inclusions is mandatory.

The results of calculation of temperature fields of structures are shown in Table 3.

The considered options for insulation of areas with heat-conducting inclusions were considered the next. Various thicknesses of the additional layer were taken over these sections and their width was determined, ensuring the fulfillment of the requirements for thermal insulation. Optimal option was considered with a smaller volume of additional insulation. The thickness of the additional layer was taken from top of the main heater. The volume of insulation for wooden and reinforced concrete beams was determined taking into account the heater located above the top of the beam to the level of the main heater.

The results of determining the optimum dimensions of the additional insulation are shown in Table 4.

Figure 4 shows the optimal options for the insulation of areas with heat-conducting inclusions, ensuring the fulfillment of the requirements of thermal insulation. 
Table 3. Heat spaces properties of the cold roof spaces after thermal modernization.

\begin{tabular}{|c|c|c|c|c|}
\hline \multirow{2}{*}{ 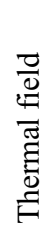 } & \multirow[b]{2}{*}{ Indicator } & \multicolumn{3}{|c|}{ The design of the cold roof spaces } \\
\hline & & By wooden beams & $\begin{array}{l}\text { By reinforced } \\
\text { concrete beams }\end{array}$ & $\begin{array}{l}\text { Made of concrete } \\
\text { slabs with upward } \\
\text { edges }\end{array}$ \\
\hline \multirow{6}{*}{1} & $R_{\text {Ered }}, \mathrm{m}^{2} \cdot \mathrm{K} / \mathrm{W}$ & 3,812 & 1,787 & 0,997 \\
\hline & $R_{q \min }, \mathrm{m}^{2} \cdot \mathrm{K} / \mathrm{W}$ & \multicolumn{3}{|c|}{4,95} \\
\hline & $\Delta T_{\text {red }},{ }^{\circ} \mathrm{C}$ & 1,2 & 2,6 & 4,6 \\
\hline & $\Delta T_{s h},{ }^{\circ} \mathrm{C}$ & \multicolumn{3}{|c|}{4} \\
\hline & $T_{\text {in }, \min ,}{ }^{\circ} \mathrm{C}$ & 19,1 & 18,7 & 17,7 \\
\hline & $T_{d},{ }^{\circ} \mathrm{C}$ & \multicolumn{3}{|c|}{10,7} \\
\hline \multirow{6}{*}{2} & $R_{\text {Ered }}, \mathrm{m}^{2} \cdot \mathrm{K} / \mathrm{W}$ & 3,563 & 1,723 & 0,935 \\
\hline & $R_{q \min }, \mathrm{m}^{2} \cdot \mathrm{K} / \mathrm{W}$ & \multicolumn{3}{|c|}{4,5} \\
\hline & $\Delta T_{\text {red }},{ }^{\circ} \mathrm{C}$ & 1,2 & 2,5 & 4,6 \\
\hline & $\Delta T_{s h},{ }^{\circ} \mathrm{C}$ & \multicolumn{3}{|c|}{4} \\
\hline & $T_{\text {in }, \min },{ }^{\circ} \mathrm{C}$ & 19,1 & 18,7 & 17,7 \\
\hline & $T_{d},{ }^{\circ} \mathrm{C}$ & \multicolumn{3}{|c|}{10,7} \\
\hline
\end{tabular}

Table 4. Heat spaces properties of the cold roof spaces after thermal modernization.

\begin{tabular}{|c|c|c|c|c|c|}
\hline \multirow{2}{*}{ 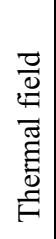 } & \multirow{2}{*}{$\begin{array}{l}\text { The design of the } \\
\text { cold roof spaces }\end{array}$} & \multicolumn{2}{|c|}{$\begin{array}{l}\text { Dimensions of an additional layer } \\
\text { of insulation over the heat- } \\
\text { conducting sections }\end{array}$} & \multirow{2}{*}{$\begin{array}{l}\text { Insulation } \\
\text { utility volume } \\
\text { per } 1 \mathrm{~m} \text { of } \\
\text { length, } \mathrm{m}^{3}\end{array}$} & \multirow{2}{*}{$\begin{array}{c}R_{\sum r e d}, \\
\mathrm{~m}^{2} \cdot \mathrm{K} / \mathrm{W}\end{array}$} \\
\hline & & Thickness, m & Width, m & & \\
\hline \multirow{10}{*}{1} & \multirow{3}{*}{ By wooden beams } & 0,03 & 0,62 & 0,0216 & 4,959 \\
\hline & & 0,04 & 0,44 & 0,0206 & 4,955 \\
\hline & & 0,05 & 0,36 & 0,021 & 4,96 \\
\hline & \multirow{4}{*}{$\begin{array}{l}\text { For reinforced } \\
\text { concrete beams }\end{array}$} & 0,04 & 0,76 & 0,0334 & 4,954 \\
\hline & & 0,05 & 0,6 & 0,033 & 4,965 \\
\hline & & 0,06 & 0,5 & 0,033 & 4,963 \\
\hline & & 0,07 & 0,44 & 0,0338 & 4,963 \\
\hline & \multirow{3}{*}{$\begin{array}{l}\text { Made of concrete } \\
\text { slabs with upward } \\
\text { edges }\end{array}$} & 0,14 & 0,82 & 0,10872 & 4,952 \\
\hline & & 0,15 & 0,76 & 0,10792 & 4,96 \\
\hline & & 0,16 & 0,72 & 0,10912 & 4,979 \\
\hline \multirow{9}{*}{2} & \multirow{3}{*}{ By wooden beams } & 0,05 & 0,46 & 0,0236 & 4,517 \\
\hline & & 0,06 & 0,38 & 0,0234 & 4,507 \\
\hline & & 0,07 & 0,34 & 0,0244 & 4,509 \\
\hline & \multirow{3}{*}{$\begin{array}{l}\text { by reinforced } \\
\text { concrete beams }\end{array}$} & 0,05 & 0,74 & 0,0388 & 4,542 \\
\hline & & 0,06 & 0,58 & 0,0366 & 4,508 \\
\hline & & 0,07 & 0,5 & 0,0368 & 4,508 \\
\hline & \multirow{3}{*}{$\begin{array}{l}\text { Made of concrete } \\
\text { slabs with upward } \\
\text { edges }\end{array}$} & 0,15 & 0,8 & 0,10976 & 4,519 \\
\hline & & 0,16 & 0,74 & 0,10816 & 4,514 \\
\hline & & 0,17 & 0,7 & 0,10876 & 4,522 \\
\hline
\end{tabular}


a)
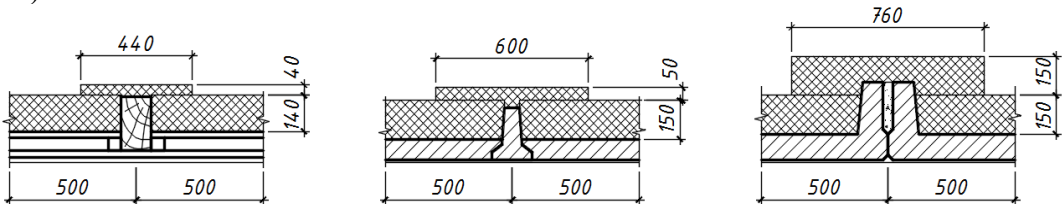

b)
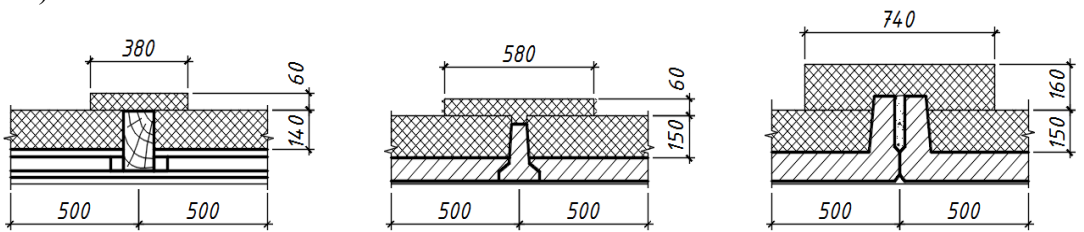

Fig. 4. Optimal insulation options for areas with heat conductive inclusions:

a) - I-st temperature field; b) - II-nd temperature field

Evaluation of the cold roofs structures spaces humidity mode after the thermal modernization performed in the climatic conditions in Poltava. Figure 5 shows the schedules of distribution for crossing the spaces of steam $e$ resiliency and saturated steam $E$ elasticity.

a)

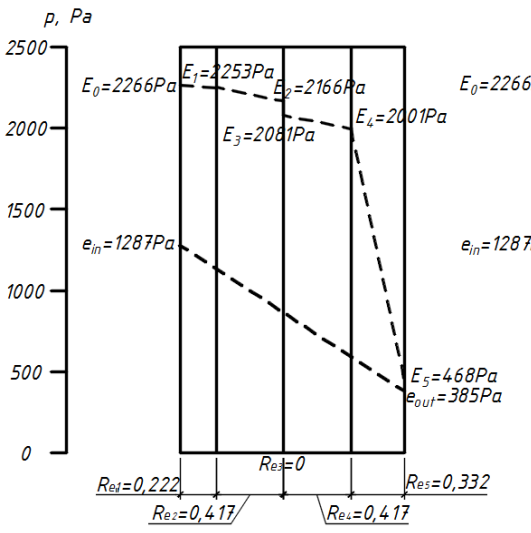

b)

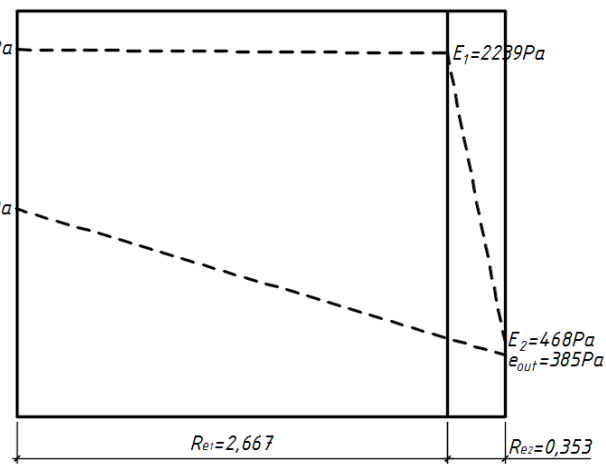

c)

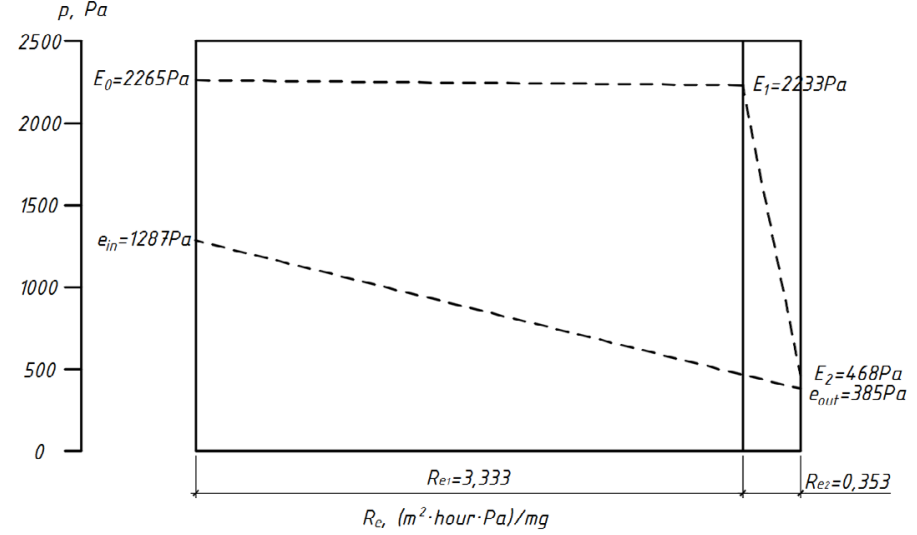

Fig. 5. The schedules of distribution for crossing the spaces of steam $e$ resiliency and saturated steam elasticity $E$ : a) - by wooden beams; b) - by reinforced concrete beams c) - made of concrete slabs with upward edges. 
The schedules show that water vapour condensation inside capping as of January does not occurs. Since January is the most unfavourable month in terms of water saturation then the water saturation is not occur during other months of the year.

Summary:

1. When cold roof spaces structures thermal modernization the additional insulation of heat conductive areas inclusions shall be performed.

2. Ignoring of these requirements reduces resistance to heat reduction from $21 \%$ to $80 \%$ and increases the heat loss through the structure.

3. The optimal circuits of additional insulation of the areas with heat conductive inclusions allow to bring the constructions considered to thermal standards.

4. Additional insulation of heat-conducting sections depends on beams step or slabs of ribs, the thermal conductivity of insulation and temperature zones.

5. In perspective it is necessary to obtain the dependence size ratio of additional insulation of the following values for the constructions considered.

\section{References}

1. R. Sztanyi, Annals of the oradea university Fascicle of Management and Technological Engineering ISSUE, 1, 126 (2015).

2. E. Megyesi, M. Brumaru, Advanced Materials Research, 899, 24 (2014).

3. M. Citterio, M. Cocco, H. Erhorn-Kluttig, EPBD Buildings Platform, 28, 4 (2008).

4. N. Norris, P. Ropell, M. Lawton, Building enclosure science \& technology conference, Atlanta, 3 (2012).

5. Z. Ma, P. Cooper, D. Daly, L. Ledo, Energy Build, 55, 889 (2012).

6. V. Murgul, MATEC Web of Conferences, 53, 01046 (2016).

7. C. Diakaki, E. Grigoroudis, N. Kabelis, D. Kolokotsa, K. Kalaitzakis, G. Stavrakakis, Energy 35, 5483 (2010).

8. N.D. Danylov, A.A. Sbakin, E.G. Slobodnikov, Housing construction, 11, 46 (2013).

9. L. Tronchin, K. Fabbri, Energy Build. 40, 1176 (2008).

10. Foucquier, F. Suard, S. Robert, L. Stephan, A. Jay, Renewable and Sustainable Energy Reviews, 23, 272 (2013). 